Article

\title{
Investigation of steady-state heat extraction rates for different borehole heat exchanger configuration from the aspect of implementation of new TurboCollector ${ }^{\mathrm{TM}}$ pipe system design
}

\author{
Tomislav Kurevija ${ }^{1 *}$, Adib Kalantar ${ }^{2}$, Marija Macenić ${ }^{3}$, Josipa Hranić ${ }^{4}$ \\ 1 Faculty of Mining, Geology and Petroleum Engineering, University of Zagreb, tkurevi@rgn.hr \\ 2 Faculty of Textiles, Engineering and Business, University of Borås, adib.kalantar@hb.se \\ 3 Faculty of Mining, Geology and Petroleum Engineering, University of Zagreb, kstrpic@rgn.hr \\ 4 Faculty of Mining, Geology and Petroleum Engineering, University of Zagreb, skoscak@rgn.hr \\ * Correspondence: tkurevi@rgn.hr; Tel.: +385-1-5535834
}

\begin{abstract}
When considering implementation of shallow geothermal energy as a renewable source for heating and cooling of the building, special care should be taken in hydraulic design of borehole heat exchanger system. Laminar flow can occur in pipes due to usage of glycol mixture at low temperature or inadequate flow rate. This can lead to lower heat extraction and rejection rates of the exchanger because of higher thermal resistances. Furthermore, by increasing flow rate to achieve turbulent flow and satisfactory heat transfer rate can lead to increase the pressure drop of the system and oversizing of circulation pump which leads to impairment of seasonal coefficient of performance at the heat pump. Most frequently used borehole heat exchanger system in Europe is double-loop pipe system with smooth inner wall. Lately, development is focused on implementation of different configuration as well as with ribbed inner wall which ensures turbulent flow in the system, even at lower flow rates. At a location in Zagreb, classical and extended thermal response test was conducted on three different heat exchanger configurations in the same geological environment. With classic TRT test, thermogeological properties of the ground and thermal resistance of the borehole were determined for each smooth or turbulator pipe configuration. Extended Steady-State Thermal Response Step Test (TRST) was implemented, which incorporate series of power steps to determine borehole extraction rate at the define steady-state heat transfer conditions of $0 /-3^{\circ} \mathrm{C}$. Results show that heat exchangers with ribbed inner pipe wall have advantages over classic double-loop smooth pipe design, in terms of greater steady state heat extraction rate and more favorable hydraulic conditions.
\end{abstract}

Keywords: Shallow geothermal, Borehole heat exchanger, Heat pump, Renewable energy, Applied thermogeology.

\section{Introduction and literature overview}

The interest of using shallow geothermal energy via borehole heat exchangers and heat pump systems is in rise in the last decades. In order to optimize the system and to determine its performance, thermal response test is usually performed on heat exchangers. Most common pipe configuration installed in boreholes is double-U (2U) or single-U (1U). Therefore these configurations, with different diameters and inside pipe lining, were chosen to compare thermogeological and hydraulical parameters and the impact they have on heat rejection/extraction rates.

The thermal response test (TRT) is common in-situ method of evaluating thermogeological properties of the ground. The procedure consists of circulating the heated fluid through borehole heat exchanger (BHE), which causes heat rejection to the ground. With the inversion of collected data, temperature response in the case of heat extraction is obtained. With such analysis the optimization 
of borehole heat exchanger field and the heat pump system is possible. Even though there is already extensive research of implementation of TRT data on optimizing the BHE system, there is space to improve and implement the research, especially when it comes to hydraulic setting. The data set of TR testing, from the Molinella (Bologna) area, was used to appraise the equivalent ground thermal conductivity and in system design [1]. The measured results were examined in accordance with the common interpretation procedure based on the first-order approximation of the solution for the infinite line source (ILS) model and then by utilizing the complete solutions of both the ILS and cylinder source models. The inverse numerical procedure (by means of CaRM tool) was also applied on the analysed measurements. The minimum misfit between the experimental and calculated values of the mean fluid temperature was found using the inverse numerical procedure, which led to conclusion that the best result is generally obtained using the inverse numerical interpretation.

The investigation and development of more precise methods for TRT control, modelling and evaluation in semi-permeable soils, with large water content, was examined by testing a pilot borehole heat exchanger [2]. The comparison of three models was preformed: two based on the ILS theory and one based on the finite-line source (FLS) scheme with the two equipment configurations; with and without strict control of rejected heat. The findings showed that the use of a PID (Proportional-Integral-Derivative) control system, to keep the rejected heat rate constant, notably reduces the noise and errors associated with the measurements, allowing more accurate analysis and thermal parameter assessments. In addition, it was proved that the use of LSQ-based identification algorithms leads to the inference of parameter values that better fit the data. The FLS approach gave better results, although the difference with the ILS is small.

Lamarche et al. [3] researched a field method to asses 2D borehole resistance and 2D internal resistance independently. Two approaches were suggested. Firstly, the temperature at the bottom of the borehole is measured at the same time as the inlet and outlet temperatures, as done in a conventional TRT. The second approach used different flow rates during the experiment to infer the internal resistance. The methods were applied to real experimental tests and compared with numerical simulations. Results implied that the resistances are dependent of the assumed temperature profile along the ground or borehole heat exchanger pipe. It was also noticed that the method using the temperature at the bottom is very sensitive to the accuracy of the temperature sensors. The observation led to conclusion that it is important to know both resistance components to predict the variation of the effective resistance when the flow rate and the height of the boreholes are changed during the design process.

In order to evaluate the thermal response of heat rejection and recovery behaviour of the ground, two thermal response tests (TRT) were conducted on the same experimental borehole heat exchanger [4]. The testing consisted from two different heat pulses enforced to the same borehole, one with 4,43 $\mathrm{kW}$ and the other with $7,64 \mathrm{~kW}$ rejected heat flux. The ground thermal conductivity and borehole thermal resistance was determined by circulating heated fluid in a U-tube type BHE, while thermocouples placed on the borehole wall measured temperature profiles of undisrupted ground as well as during the recovery period. The analysis indicated that the true undisturbed state after rejected heat flux cannot be reached in short time while the use of higher rejection heat flux reduces the influence of the ground's inhomogeneity on the results obtained [4].

Kurevija et al. [5] used novel method, steady-state thermal response step test (TRST), to determinate heat rejection rates for passive and active cooling in a steady state regime. Classic and extended step thermal response test were conducted on three different locations in Zagreb with similar geological setting. The results showed that that the data from the test are not only applicable to determinate the thermal properties of the ground but can be useful for design optimization of the BHE field. The analysis showed that the coaxial system is not suitable for passive cooling demands given that the heat rejection rate is only between $8-11 \mathrm{~W} / \mathrm{m}$. Furthermore, for they require large borehole length, the coaxial heat exchangers should always be designed for an active cooling regime with an operation of a heat pump compressor in a classical, vapour compression refrigeration cycle.

Kurevija et al. [6] found that the accuracy of effective ground thermal conductivity measurement using the thermal response test (TRT) can be investigated. The new method, which observes the falloff temperature decline after the power test, is based on a premise of analogy between TRT and 
petroleum well testing, since the origin of both procedures lies in the diffusivity equation with solutions for heat conduction or pressure analysis during radial flow. The insight in the analysis conducted in this work is provided for five different power steps, and with both direct and reverse flow regimes. The findings underscore that the ground conductivity value could vary by as much as $25 \%$, depending on test time, seasonal period and power fluctuations, while the thermal conductivity obtained from the falloff period provided more stable values, with only a $10 \%$ value variation.

Beier et al. [7] studied a borehole heat transfer model that uses a transient weighting factor to calculate the average circulating fluid temperature along the borehole has been applied to analyse multi-flow rate thermal response tests (MFR-TRT) The model accounts for short-circuiting by an analytically computed weighting factor that is used to determine the mean fluid temperature. It was stated that both; the effective borehole thermal resistance model and the weighting factor give quite good results a few hours after a step change in flow rate, the weighting factor model gives much better results in the first few hours after a step change in flow rate.

Beier [8] studied the new parameter estimation method to interpret the TRT data using the temperature derivative in addition to the usual transient temperature curve. The method is applied and demonstrated using three TRT data sets. The procedure uses parameter estimation techniques (non-linear least squares) to match the borehole heat transfer model to measured temperature and the associated derivative curves. An estimation for the ground volumetric heat capacity is provided in addition to the ground thermal conductivity and effective borehole resistance. Conclusion suggested that without the derivative curve parameter estimation gives unrealistic values of ground volumetric heat capacity, if the three unknown parameters are to be determined. Therefore, temperature derivative curve enhances the interpretation of thermal response tests on borehole heat exchanger.

Urchueguia et al. [9] examined the results of a number of TRT experiments performed at the same location over a number of years. The main goal was to numerically asses the influence of groundwater flow heat advection using moving infinite and FLS theories, as well as to analyse the influence of factors such as test duration, sensor accuracy, and external thermal influences. The results showed that used infinite and finite line-source models, as well as the moving line-source models, could accurately represent experimental temperature evolution. However, care has to be taken regarding the significance parameters extracted and their reproducibility and stability. It was concluded that these features can be improved if data from the first test days are disregarded for the analysis, obtaining a much faster convergence to the definitive soil parameter estimates.

Pasquier [10] identified four new first-order approximation models using the time derivative of fluid temperature to interpret the first hours of the heating and recovery phases of a TRT results. Throughout the interpretation models tested on real and synthetic data sets, it was noticed that analysing the time derivatives, measured during the first three hours of a real TRT with a constrained first-order approximation model, can provide a thermal conductivity estimation within $10 \%$ of a reference value. The findings could present a new group of interpretation methods that could potentially shorten the duration of thermal response tests from 72 to 3 hours.

Fossa et al. [11] studied measurements from a pulsated TRT that has been processed by 3 different inverse solution algorithms. The methods included the use of the temporal superposition techniques, the use of the ILS and FLS solutions for the semi-infinite ground medium and even a resistance/capacitance method (the TRC algorithm). The results led to a conclusion that performing a long PTRT can filter out the impact of the interpretation model on the interpretation outcome and improve the identification of the borehole thermal resistance.

\section{Theoretical background}

The mathematical model, which describes the extraction or rejection of the heat in the underground, is based on the heat diffusivity equation. Fourier [12] established the model, known as 
Fourier's law, and it describes conductive heat transfer in homogeneous and isotropic environment. When using the cylindrical coordinates, it is expressed as:

$$
\frac{1}{r} \frac{\partial}{\partial r}\left(r \frac{\partial T}{\partial r}\right)=\frac{\lambda}{\rho c_{p}} \frac{\partial T}{\partial t}
$$

Where the expression $\lambda / \rho c$ Kelvin described as thermal diffusivity, $\alpha\left(\mathrm{m}^{2} / \mathrm{s}\right)$. Ingersoll and Zobel [13] describe the Fourier's law of heat conduction, in solids, with partial differential equation. Using cylindrical coordinates:

$\alpha\left[\frac{\partial^{2} T}{\partial r^{2}}+\frac{1}{r} \frac{\partial T}{\partial r}+\frac{1}{r^{2}} \frac{\partial^{2} T}{\partial f^{2}}+\frac{\partial^{2} T}{\partial z^{2}}\right]=\frac{\partial T}{\partial t}$

There are two main analytical models when solving (2) - line source and cylindrical model. The solutions are dependent on boundary conditions taken into account for each of the model. However, in both models, the term $\frac{1}{r^{2}} \frac{\partial^{2} T}{\partial f^{2}}$ is neglected [14]. There are two main approaches when solving for line source model- the infinite line source and finite line source model. The infinite line source model, first described and solved by lord Kelvin, describes radial heat flow. Carslaw and Jaeger [15] gave a well-known solution for infinite line source model, used for describing heat extraction or rejection when using borehole heat exchangers. The model assumes that the borehole is an infinite line source in homogenous and isotropic medium. The solution describes the temperature distribution as a function of time at some distance in relation to the borehole. Since the vertical component is neglected $\left(\partial^{2} T / \partial z^{2}=0\right.$ ) only radial heat flow is observed. Analytical solution includes the use of exponential integral or its simplified form, with certain constrictions [15-19]. In the case of heat rejection, the expression for determining temperature response, while performing the thermal response test is:

$T\left(r_{b}, t\right)=T_{0}+\frac{q^{\prime}}{4 \pi \lambda}\left(\operatorname{Ei}\left(\frac{r_{b}^{2}}{4 \alpha t}\right)\right)$

where $T_{i}$ represents the undisturbed ground temperature and Ei represents the exponential integral, which can be approximated with natural logarithmic function, in cases when $\left(4 \alpha t / r^{2}\right)>50$ :

$-E_{i}(-x) \cong-\ln (\gamma x) \cong-\ln \left(e^{\gamma} x\right)=\ln \left(\frac{1}{x}\right)-\gamma=\ln \left(\frac{1}{x}\right)-0,5772$

Then the final expression is:

$T\left(r_{b}, t\right)=T_{0}-\frac{q^{\prime}}{4 \pi \lambda}\left(\ln \left(\frac{e^{\gamma} r_{b}^{2}}{4 \alpha t}\right)\right)=T_{0}-\frac{q^{\prime}}{2 \pi \lambda}\left(\ln \frac{r_{b}^{2}}{4 \alpha t}+0,5772\right)=T_{0}-\frac{q^{\prime}}{4 \pi \lambda}\left(\ln \frac{r_{b}^{2}}{\alpha t}-0,80907\right)$

Where $\frac{q^{\prime}}{4 \pi \lambda}=\kappa$ is the slope of the line when plotting $\mathrm{T}$ vs. $\ln (\mathrm{t})$ and it is standardized principle to obtain effective ground thermal conductivity [19].

The finite line source (FLS) model considers the vertical component $\left(\partial^{2} T / \partial z^{2} \neq 0\right)$ as one of the boundary conditions, i.e. the finite length of the heat exchanger is considered. Claesson and Eskilson $[14,16,20]$ gave the solution for temperature at the borehole wall, and in the case of heat rejection it is:

$$
T\left(r_{b}, t\right)=T_{0}+q^{\prime} \frac{1}{2 \pi \lambda} g\left(\frac{t}{t_{s}}, \frac{r_{b}}{H}\right)
$$

where $\mathrm{g}$ represents the so-called g-function (or Eskilson's g-function) and is described as dimensionless temperature response factor. The g-function is calculated as: 
$g\left(\frac{t}{t_{s}}, \frac{r}{H}\right)= \begin{cases}\ln \left(\frac{H}{2 r}\right) & , t>t_{s} \\ \ln \left(\frac{H}{2 r}\right)+\frac{1}{2} \ln \left(\frac{t}{t_{s}}\right) & , \frac{5 r^{2}}{\alpha}<t<t_{s}\end{cases}$

Influence of thermal properties of the soil are expressed through the factor $t_{s}$, which represents the time at which the steady state heat flow is achieved:

$t_{s}=\frac{H^{2}}{9 \alpha}(8)$

In the denominator this equation contains a value of thermal diffusivity, $\alpha$, which is assumed from the drilling data or catalogue values for different types of soil. Since this is not the exact value, this method of determining the duration of the transition period can cause further error in interpretation, especially for highly heterogeneous ground. Much more accurate grapho-analytical method, the so called derivation curve principle, can be implemented to determine transition from unsteady state heat flow to relevant semi-steady state heat flow regime. Typical shape of derivation curve for a TRT is shown on Figure 4, where each data point is derivate as:

$\left(\frac{d y}{d x}\right)_{A}=\frac{\left(\frac{y_{1}}{x_{1}} x_{2}+\frac{y_{2}}{x_{2}} x_{1}\right)}{\left(x_{1}+x_{2}\right)}$

In order to determine the temperature inside the borehole heat exchanger the value of ground and borehole thermal resistance are determined. While in the petroleum industry the skin factor describes the damaged zone near the borehole, which affects the fluid flow into the well, in thermogeology it describes the thermal resistance to the heat flow, imposed by the borehole itself. It depends mainly on pipe configuration, grout used for cementing of the borehole as well as on fluid and flow properties, and it is expressed as:

$\Delta T_{\text {skin }}=s\left(\frac{q^{\prime}}{2 \pi \lambda}\right)=R_{b}^{\prime} \cdot q^{\prime}$ where s is: $\quad s=\frac{1}{2} \ln \left(\frac{e^{\gamma} r_{w}^{2}}{4 \alpha t_{p}}\right)-\frac{\left(T_{i}-T_{p}\right) 2 \pi \lambda}{q^{\prime}}$

Kurevija et al. [5] showed that implementing the steady state thermal response step test (TRST) is helpful with the system optimization. The step test is carried out by imposing different heat pulses (heat rejection rates) after a certain period. For calculating skin factor, $\mathrm{s}$, and $\Delta \mathrm{T}_{\text {skin, }}$ expressions in [6] can be used. By using Eskilson's g-function analysis it is possible to analytically describe the temperature response of conducted TRST for each step, by superimposing each consecutive step on the steps already conducted [14, 16, 20]. Therefore, for any arbitrary heat pulse, in case of TRT-heat rejection pulse, thermal response can be found. The superposition principle suggests that, in the case of performing TRT with three different pulses, that the first thermal pulse is imposed during the entire testing period. Each consecutive pulse is superimposed on the previous one. The general expression for average fluid temperature inside the BHE, for different heat rejection [14] is:

$T_{f}(t)=T_{i}+\left[\frac{1}{2 \pi \lambda} \sum_{i=1}^{n}\left(q_{i}^{\prime}-q_{i-1}^{\prime}\right) g_{i}\right]+\Delta T_{s k i n}$

For example, in the case of three different heat rejection pulses the average temperature of the circulating fluid would be calculated as:

First step:

$T_{f}(t)=T_{0}+\left[\left(\frac{q_{1}^{\prime}}{2 \pi \lambda}\right) \cdot g_{t_{1}}\right]+\Delta T_{s k i n 1}$

Second step: 


$$
T_{f}(t)=T_{0}+\left(\frac{1}{2 \pi \lambda}\right)\left[\left(q_{1}^{\prime} \cdot g_{t_{1}}\right)-\left(-q_{2}^{\prime}+q_{1}^{\prime}\right) \cdot g_{t_{2}-t_{1}}\right]+\Delta T_{\text {skin } 2}
$$

Third step:

$$
T_{f}(t)=T_{0}+\left(\frac{1}{2 \pi \lambda}\right)\left[\left(q_{1}^{\prime} \cdot g_{t_{1}}\right)-\left(\left(-q_{2}^{\prime}+q_{1}^{\prime}\right) \cdot g_{t_{2}-t_{1}}\right)-\left(\left(-q_{3}^{\prime}+q_{2}^{\prime}\right) \cdot g_{t_{3}-t_{2}}\right)\right]+\Delta T_{\text {skin } 3}
$$
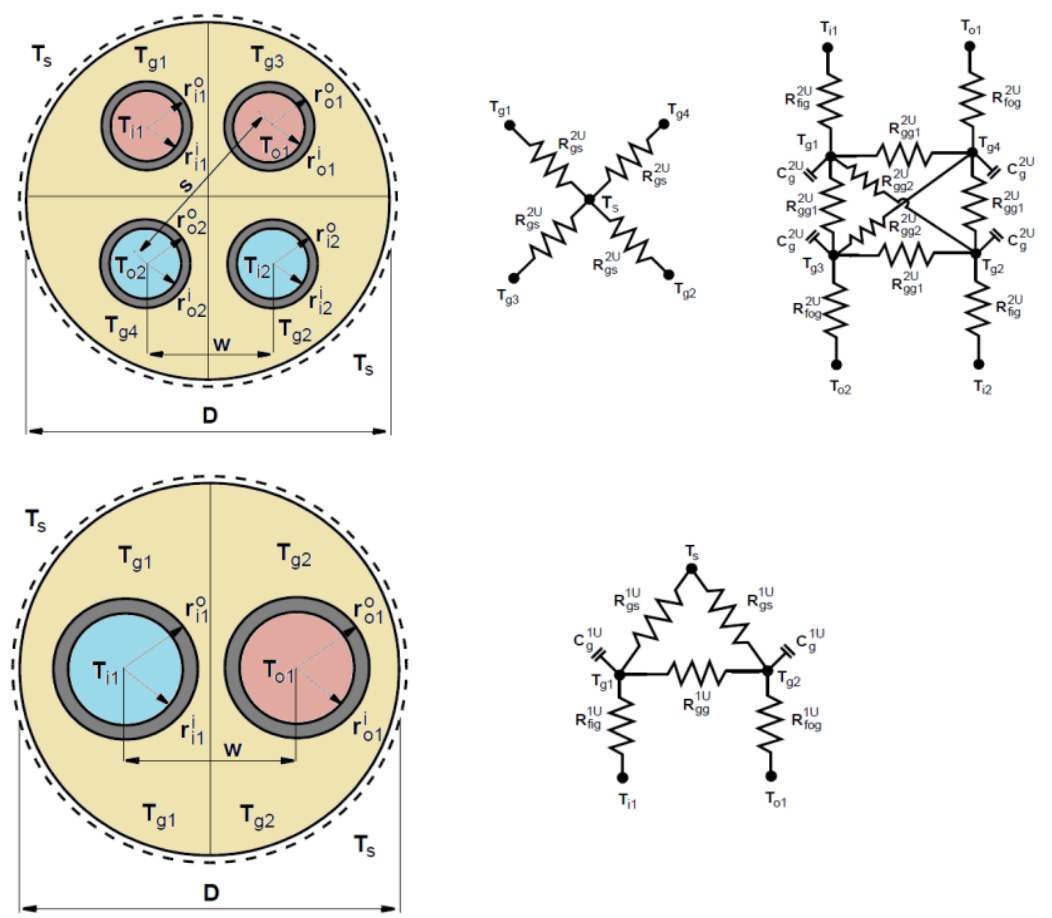

Figure 1. a) 2U-pipe arrangement b) 1U-pipe arrangement [21]

Analysis of borehole thermal resistance for a double-U (2U) heat exchanger configuration is described in detail by Al-Khoury [21], using method of eight different components: two pipes-in (marked as $\mathrm{i}_{1}$ and $\mathrm{i}_{2}$ ), two pipes-out (marked as $\mathrm{o}_{1}$ and $\mathrm{o}_{2}$ ) and four zones of grout material (marked as $g_{1}, g_{2}, g_{3}$ and $\left.g_{4}\right)$. The four pipe components transfer heat across cross-sectional areas and exchange fluxes across their surface areas. The radial heat transfer from the pipes is directed to the grout zones which exchange heat directly to the surrounding soil, denoted as s, and to other contacted grout zones. Double-U pipe arrangement involves several material and geometry parameters, as shown on Figure $2 \mathrm{a}$, which determines overall thermal resistance of the borehole.

The analysis for a single-U pipe (1U) borehole thermal resistance is similar to the 2U-pipe, but with less components in the configuration, as seen on Figure $2 b$. The configuration consists of: one pipe-in (marked as $\mathrm{i}_{1}$ ), one pipe-out (marked as $\mathrm{o}_{1}$ ) and two zones of grout material (marked as $\mathrm{g}_{1}$ and $\mathrm{g}_{2}$ ). The radial heat transfer process can be described the same as in the case of 2U-pipe configuration.

\section{Experimental site setting}

The thermal response test was conducted in the city of Zagreb, Croatia, at the location as shown on Figure 2. On the figure detailed geological map of the city of Zagreb and its surrounding area is shown [22]. The area is located mostly on the Zagreb aquifer system, which is of Quaternary age. The aquifer is mostly comprised of Middle and Upper Pleistocene, and Holocene sediments. The location of the BHEs is near the Zagreb aquifer boundary. The lithological makeup is also shown on Figure 2. Up to 110 meters, the underground is mostly comprised of gravel, sand and clay in various ratios. 


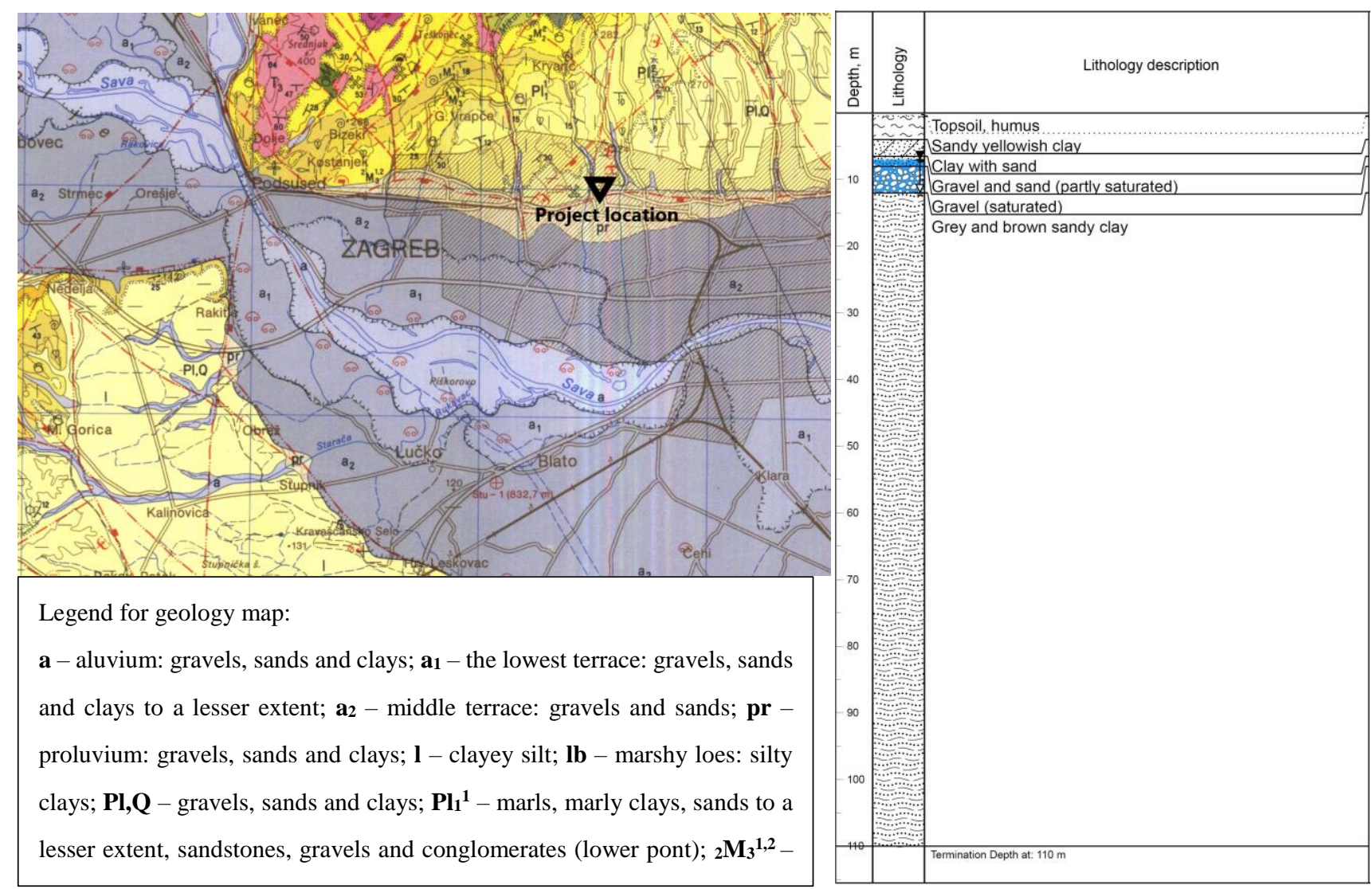

Figure 2. Detailed geological map with BHEs location and general lithology column of the project site.

At the residential project site, three vertical boreholes for heating and cooling purposes were drilled up to $110 \mathrm{~m}$. The diameter of each of the borehole is $152 \mathrm{~mm}$. The project site during the drilling operations is seen on Figure 4a. The thermal response test was carried out on three BHEs with different geometrical setting, and two pipe arrangements. The undisturbed ground temperature was measured at $15,2^{\circ} \mathrm{C}$, with fluid flow of $0,45 \mathrm{l} / \mathrm{s}$. Fluid is comprised solely out of water, with viscosity presumed to be around $1 \mathrm{mPa}$.

The first BHE, designated as BHE-1, is equipped with polyethylene 2U-pipe (D32mm PE100 SDR11) with a smooth inner wall. Such design is most often used borehole heat exchanger in Europe. The total measuring time, while conducting the TRT, was 118 hours.

The second heat exchanger, denoted as BHE-2, is also equipped with 2U-pipe (D32mm PE100 SDR11) with a ribbed inner wall, as showed on Figure 4c. Heat exchanger pipes, with a ribbed inner wall or micro fins, are also commercially known as TurboCollector ${ }^{\mathrm{TM}}$ [24],. Their function is to maintain a turbulent fluid flow, even in situations where Reynolds number will point to the laminar type fluid flow. The study of Acuna [23] showed that pipes with the so-called grooves have lower values of thermal resistance which points to higher heat transfer, when compared to pipes with smooth inner lining. Moreover, the comparison of hydraulic properties, showed that the pressure drop is much lower than classic, smooth, BHE pipe. This results in lower consumption of the circulating pump, which in turn affects the operating costs.

The third borehole, BHE-3, was equipped with a novel single TurboCollector ${ }^{\mathrm{TM}}$ 1U-pipe (D45mm PE100 SDR11). The three different pipe configurations were used to determine the effect on overall heating/cooling extraction/rejection rate. 


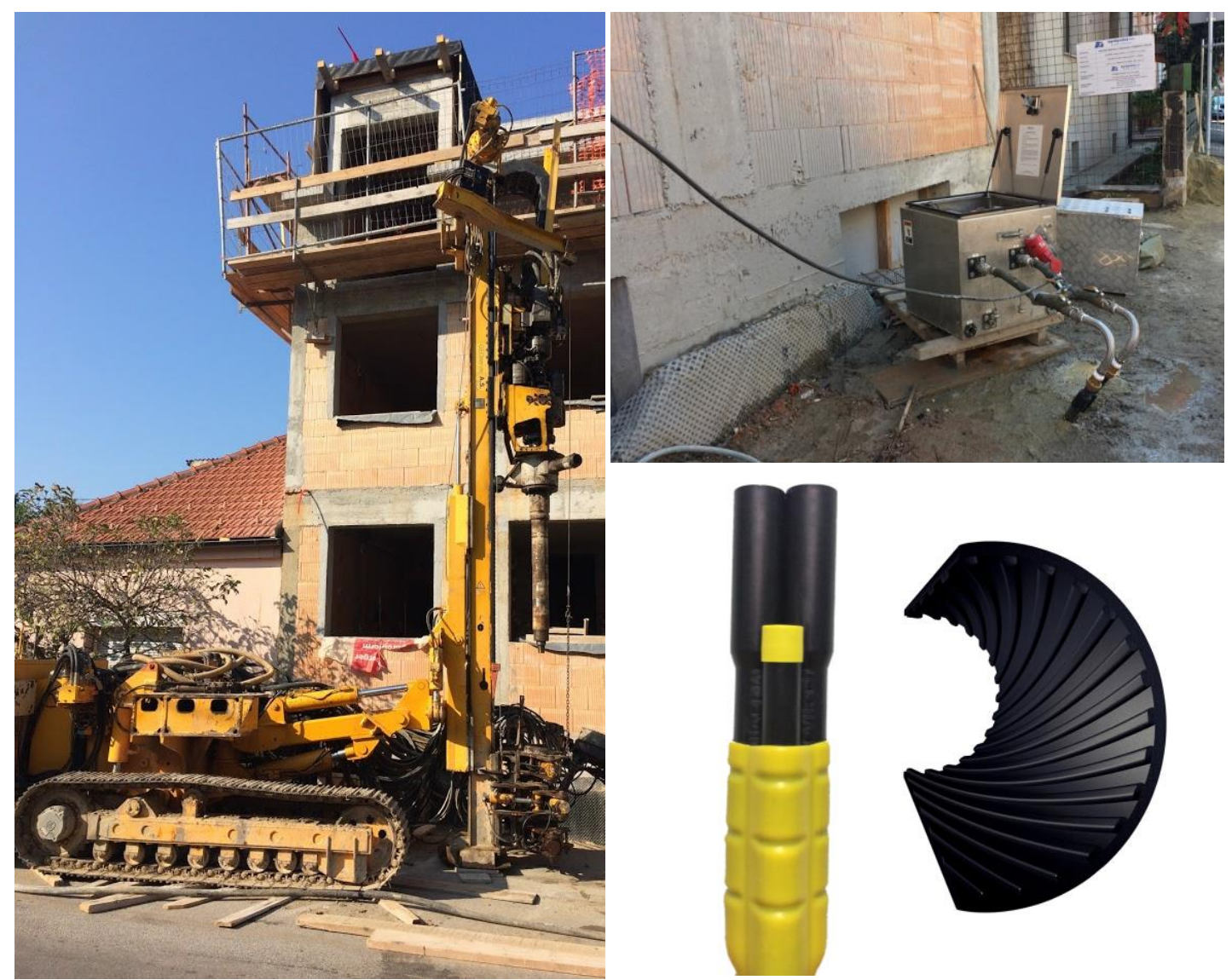

Figure 3. a) Drilling of the BHEs b) performing the thermal response test c) TurboCollector ${ }^{\mathrm{TM}}$ pipe

\section{Results and Discussion}

Measurements on three borehole heat exchangers were conducted in October 2018 with TRT apparatus Geocube GC500. Equipment has maximum available power of electric heaters of 9,0 kW @ $240 \mathrm{~V}$. Internal logger collects 5-min interval data about inlet and outlet water temperature, air temperature, flow, voltage and electric current. Sealed temperature sensors (resistance temperature detectors - RTD) on inlet and outlet connection have accuracy of $\pm 0,2{ }^{\circ} \mathrm{C}$ from $0{ }^{\circ} \mathrm{C}$ to $50^{\circ} \mathrm{C}$.

Testing procedure was setup as a classic TRT heat rejection initial step of $6,5 \mathrm{~kW}$, with duration of approximately $63 \mathrm{hr}$, followed with two additional steps with lower rejection rate where stabilization of borehole temperature was observed. Second heat step of 4,5 kW lasted approximately $24 \mathrm{hr}$, while last heat step of 2,4 kW was conducted approximately for $33 \mathrm{hr}$.

In the initial period of TRT with the pump circulation and electric heater off, it can be seen that the value of undisturbed ground temperature is roughly $15,0{ }^{\circ} \mathrm{C}$. To determine the effective ground thermal conductivity coefficient, it is necessary to plot average temperature of circulating fluid data vs. natural logarithm of time, $\ln (\mathrm{t})$. After switching on the TRT heaters, average temperature in the borehole heat exchanger begins to grow as a function of ground thermal conductivity and borehole thermal resistance. To calculate the ground thermal conductivity coefficient, on Figure 4 linear trendline is drawn in the range where semi-steady state heat flow exists for both heat exchange systems (where derivation curve falls below 0,5 which equals around 10 hours for all of the 3 boreholes). Slope of straight line portion is then determined, and by using the Eq.(5) ground thermal conductivity is calculated (presented in Table 1). 

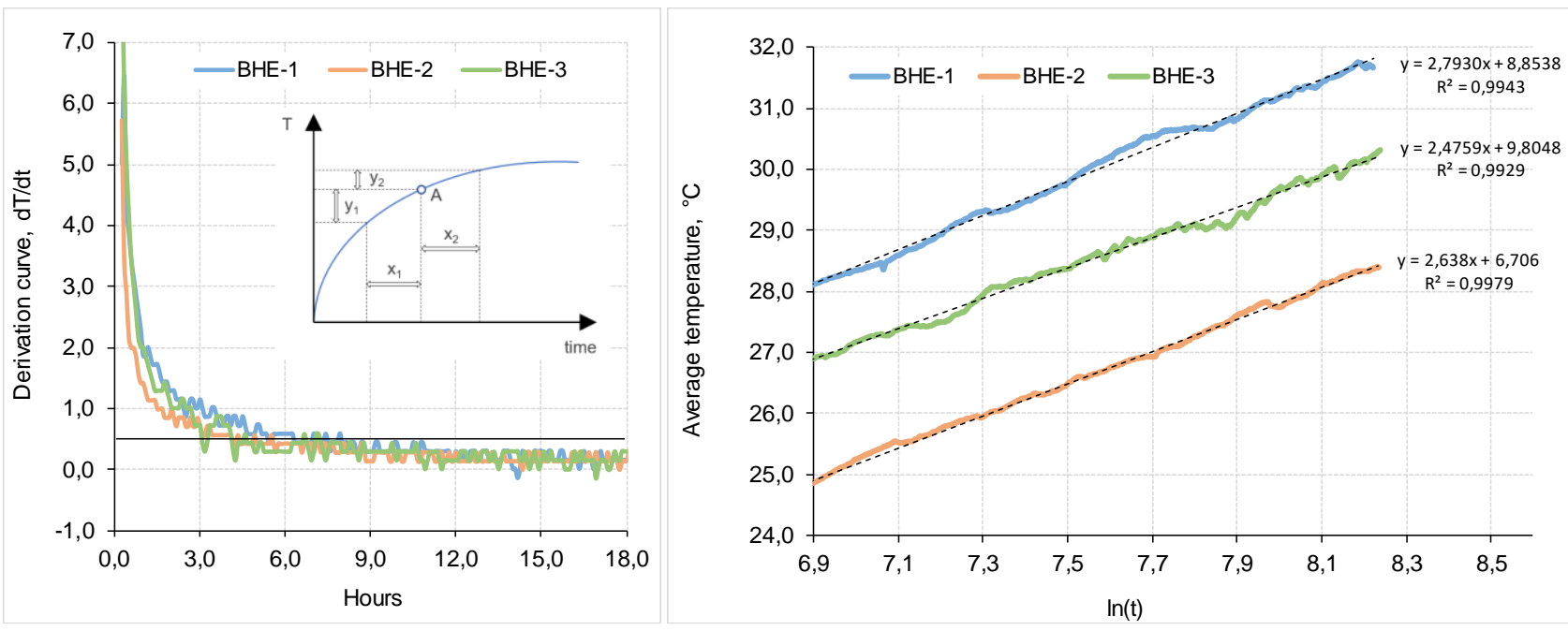

Figure 4. Determination of semi-steady state heat flow period and determination of ground heat conductivity

Figure 5. show analysis of extended testing, with an introduction of a series of fall-off tests with lower values of heat power for each of the steady-state steps (so called Thermal Response Step Test - TRST). As seen from tests results shown on Figure 5 it is obvious that each of the additional two fall-off steps, which lasted for at least $24 \mathrm{hr}$, have reached a steady-state heat flow conditions. This method can give reliable information on the relation between peak load working conditions of the heat pump system and steady-state entering source temperature from the bore field. This means that for certain heat rejection or extraction rate, temperature in the borehole will stabilize and exchanger could work for longer period without additional rise or drop in temperature, depending on summer or winter operation regime.

Table 1 shows entire collected temperature data from Thermal Response Step Test with temperature stabilization values in a function of heat rejection rate, as well as inversed temperature data for a case of heat extraction. Since in first step steady-state was not achieved, using Finite Line source method (FLS)

Total of four steady-state points are then extracted from Figure 5 and presented in Table 1, including initial static temperature conditions. Table 2 shows obtained thermogelogical data as well as borehole resistance or skin factor. 
Table 1. Thermal Response Step Test obtained temperature data

\begin{tabular}{|c|c|c|c|c|c|c|c|c|}
\hline & $\begin{array}{l}\text { BHE-1 } \\
\text { 2U D32 } \\
\text { smooth }\end{array}$ & $\begin{array}{l}\text { TRT } \\
\text { time }\end{array}$ & $\begin{array}{l}\text { Heat } \\
\text { power }\end{array}$ & $\begin{array}{l}\text { Heat } \\
\text { power } \\
\text { st. dev. }\end{array}$ & $\begin{array}{l}\text { Heat } \\
\text { power } \\
\text { st. err. }\end{array}$ & $\begin{array}{l}\text { Cooling } \\
\text { cycle }\end{array}$ & $\begin{array}{l}\text { Heating } \\
\text { cycle } \\
\text { (inversed) }\end{array}$ & $\begin{array}{l}\text { Rejected } \\
\text { heat TRT }\end{array}$ \\
\hline step & heat flow regime & $\mathrm{hr}$ & $\mathrm{W} / \mathrm{m}$ & & & $\mathrm{EST}^{\circ} \mathrm{C}$ & EST inv. ${ }^{\circ} \mathrm{C}$ & $\mathrm{kWh}$ \\
\hline 1. & unsteady & 62,1 & 59,8 & 1,33 & 0,049 & 29,7 & 0,6 & 408,4 \\
\hline 1 a. & $\begin{array}{l}\text { semi-steady } \\
\text { (FLS) }\end{array}$ & 240,0 & 59,8 & - & - & 33,6 & $-3,2$ & - \\
\hline 2. & steady state & 23,9 & 40,9 & 0,35 & 0,021 & 27,0 & 3,4 & 107,7 \\
\hline 3. & steady state & 32,7 & 21,2 & 0,23 & 0,011 & 22,9 & 7,5 & 76,5 \\
\hline \multirow[t]{2}{*}{4.} & $\begin{array}{l}\text { initial } \\
\text { conditions }\end{array}$ & 0,0 & 0,0 & - & - & 15,2 & 15,2 & 0,0 \\
\hline & $\begin{array}{l}\text { BHE-2 } \\
\text { 2U D32 } \\
\text { ribbed }\end{array}$ & $\begin{array}{l}\text { TRT } \\
\text { time }\end{array}$ & $\begin{array}{r}\text { Heat } \\
\text { power }\end{array}$ & $\begin{array}{r}\text { Heat } \\
\text { power } \\
\text { st. dev. }\end{array}$ & $\begin{array}{r}\text { Heat } \\
\text { power } \\
\text { st. err. }\end{array}$ & $\begin{array}{r}\text { Cooling } \\
\text { cycle }\end{array}$ & $\begin{array}{l}\text { Heating } \\
\text { cycle } \\
\text { (inversed) }\end{array}$ & $\begin{array}{r}\text { Rejected } \\
\text { heat TRT }\end{array}$ \\
\hline 1. & unsteady & 62,8 & 58,7 & 0,66 & 0,024 & 27,0 & 3,4 & 405,3 \\
\hline $1 a$. & $\begin{array}{l}\text { semi-steady } \\
\text { (FLS) }\end{array}$ & 240,0 & 58,7 & - & - & 30,5 & $-0,1$ & - \\
\hline 2. & steady state & 24,0 & 40,8 & 0,54 & 0,032 & 25,0 & 5,4 & 107,8 \\
\hline 3. & steady state & 33,4 & 21,5 & 0,28 & 0,014 & 21,8 & 8,6 & 79,2 \\
\hline \multirow[t]{2}{*}{4.} & $\begin{array}{l}\text { initial } \\
\text { conditions }\end{array}$ & 0,0 & 0,0 & - & - & 15,2 & 15,2 & 0,0 \\
\hline & $\begin{array}{l}\text { BHE-3 } \\
1 \mathrm{U} \text { D45 } \\
\text { ribbed }\end{array}$ & $\begin{array}{l}\text { TRT } \\
\text { time }\end{array}$ & $\begin{array}{r}\text { Heat } \\
\text { power }\end{array}$ & $\begin{array}{r}\text { Heat } \\
\text { power } \\
\text { st. dev. }\end{array}$ & $\begin{array}{r}\text { Heat } \\
\text { power } \\
\text { st. err. }\end{array}$ & $\begin{array}{r}\text { Cooling } \\
\text { cycle }\end{array}$ & $\begin{array}{l}\text { Heating } \\
\text { cycle } \\
\text { (inversed) }\end{array}$ & $\begin{array}{r}\text { Rejected } \\
\text { heat TRT }\end{array}$ \\
\hline 1. & unsteady & 63,0 & 58,8 & 0,79 & 0,029 & 28,9 & 1,6 & 407,2 \\
\hline 1 a. & $\begin{array}{l}\text { semi-steady } \\
\text { (FLS) }\end{array}$ & 240 & 58,8 & - & - & 32,1 & $-1,7$ & - \\
\hline 2. & steady state & 24,5 & 40,0 & 0,42 & 0,025 & 26,1 & 4,3 & 107,9 \\
\hline 3. & steady state & 33,4 & 20,7 & 0,22 & 0,011 & 22,2 & 8,2 & 76,2 \\
\hline 4. & $\begin{array}{l}\text { initial } \\
\text { conditions }\end{array}$ & 0,0 & 0,0 & - & - & 15,2 & 15,2 & 0,0 \\
\hline
\end{tabular}

On the measured data and obtained temperature response with three different heat rejection rates, the FLS method was done which implements the so-called Eskilson's g-function. The calculation was done with results of previously calculated thermogeological data, like ground thermal conductivity. The results show a very good match and temperature response of calculated data with the results of TRT data, which can be seen on Figure 5. It has to be pointed out, that the gfunction for designated time periods ( $g_{t 1}, g_{t 2-t 1}, g_{t 3-t 2}$ ) in equations (11), (12) and (13) represent calculations for cumulative time for intended step. Using simple statistical analysis, such as sum of squares of difference, could provide exactly which thermal conductivity coefficients are of statistical significance. Sum of Squares or Variation (SUMXMY2 function in MS Excel) is a statistical technique used in regression analysis to determine the dispersion of data points. In a regression analysis, the goal is to determine how well a data series (in this case measured EST) can be fitted by a function which might help to explain how the data series was generated (in this case FLS with g-functions). The sum of squares is used as a mathematical way to find the function which best fits (varies least) from the measured data. In Table 2. statistical results are presented in a way of solver solution where 
function SUMXMY2 approaches zero for a best fit of thermal conductivity and a thermal diffusivity parameter. It could be noticed that measured conductivities from a TRT on three boreholes varies between $1,70-1,89 \mathrm{~W} / \mathrm{m}{ }^{\circ} \mathrm{C}$, while conductivity obtained by a best fitting FLS solution with SUMXMY2, when approaching to zero value, is between $1,62-1,87^{\circ} \mathrm{C}$. This procedure gives high confidence in obtained results.

Table 2. Thermal Response Step Test obtained temperature data

\begin{tabular}{|c|c|c|c|c|c|c|}
\hline & BHE-1 & Skin & $\Delta T$ & Measured $\lambda$ & Fitted $\lambda F L S$ & Fitted $\alpha$ \\
\hline & 2U D32 smooth & factor & skin & $1^{\text {st }}$ step & & FLS \\
\hline step & heat flow regime & - & ${ }^{\circ} \mathrm{C}$ & $\mathrm{W} / \mathrm{m}^{\circ} \mathrm{C}$ & $\mathrm{W} / \mathrm{m}^{\circ} \mathrm{C}$ & $\mathrm{m}^{2} /$ day \\
\hline 1. & unsteady & 0,78 & 4,60 & 1,70 & \multirow{3}{*}{1,62} & \multirow{3}{*}{0,060} \\
\hline 2. & steady state & 0,93 & 3,70 & - & & \\
\hline \multirow[t]{3}{*}{3.} & steady state & 1,31 & 2,70 & - & & \\
\hline & BHE-2 & Skin & $\Delta T$ & Measured $\lambda$ & Fitted $\lambda$ FLS & Fitted $\alpha$ \\
\hline & 2U D32 ribbed & factor & skin & $1^{\text {st }}$ step & & FLS \\
\hline 1. & unsteady & 0,74 & 3,80 & 1,77 & \multirow{3}{*}{1,81} & \multirow{3}{*}{0,036} \\
\hline 2. & steady state & 0,88 & 3,17 & - & & \\
\hline \multirow[t]{3}{*}{3.} & steady state & 1,25 & 2,36 & - & & \\
\hline & BHE-3 & Skin & $\Delta T$ & Measured $\lambda$ & \multirow[t]{2}{*}{ Fitted $\lambda$ FLS } & Fitted $\alpha$ \\
\hline & 1U D45 ribbed & factor & skin & $1^{\text {st }}$ step & & FLS \\
\hline 1. & unsteady & 1,03 & 5,15 & 1,89 & \multirow{3}{*}{1,87} & \multirow{3}{*}{0,049} \\
\hline 2. & steady state & 1,20 & 4,10 & - & & \\
\hline 3. & steady state & 1,59 & 2,82 & - & & \\
\hline
\end{tabular}

As seen from Table 1, each of the performed heat steps is defined with its stabilized temperature, where steady-state heat transfer is achieved. As an additional zero power step, initial temperature conditions are introduced, in this case $15,2{ }^{\circ} \mathrm{C}$ as an effective borehole temperature. This step-testing method can give reliable information on the relation between working conditions of the heat pump system and steady-state entering source temperature from the bore field in cooling and heating regime. This means, that for certain heat rejection or extraction rate, temperature in the borehole will stabilize and system can work for longer period without additional rise or subcooling of the borehole temperature.

By setting the steady-state temperature in each of the steps as separate points (Table 1.), it is possible to construct the heat rejection and extraction diagram $(\mathrm{W} / \mathrm{m})$ as the function of the desired inlet temperature (EST - Entering source temperature) to the heat pump, as seen from Figure 6. 

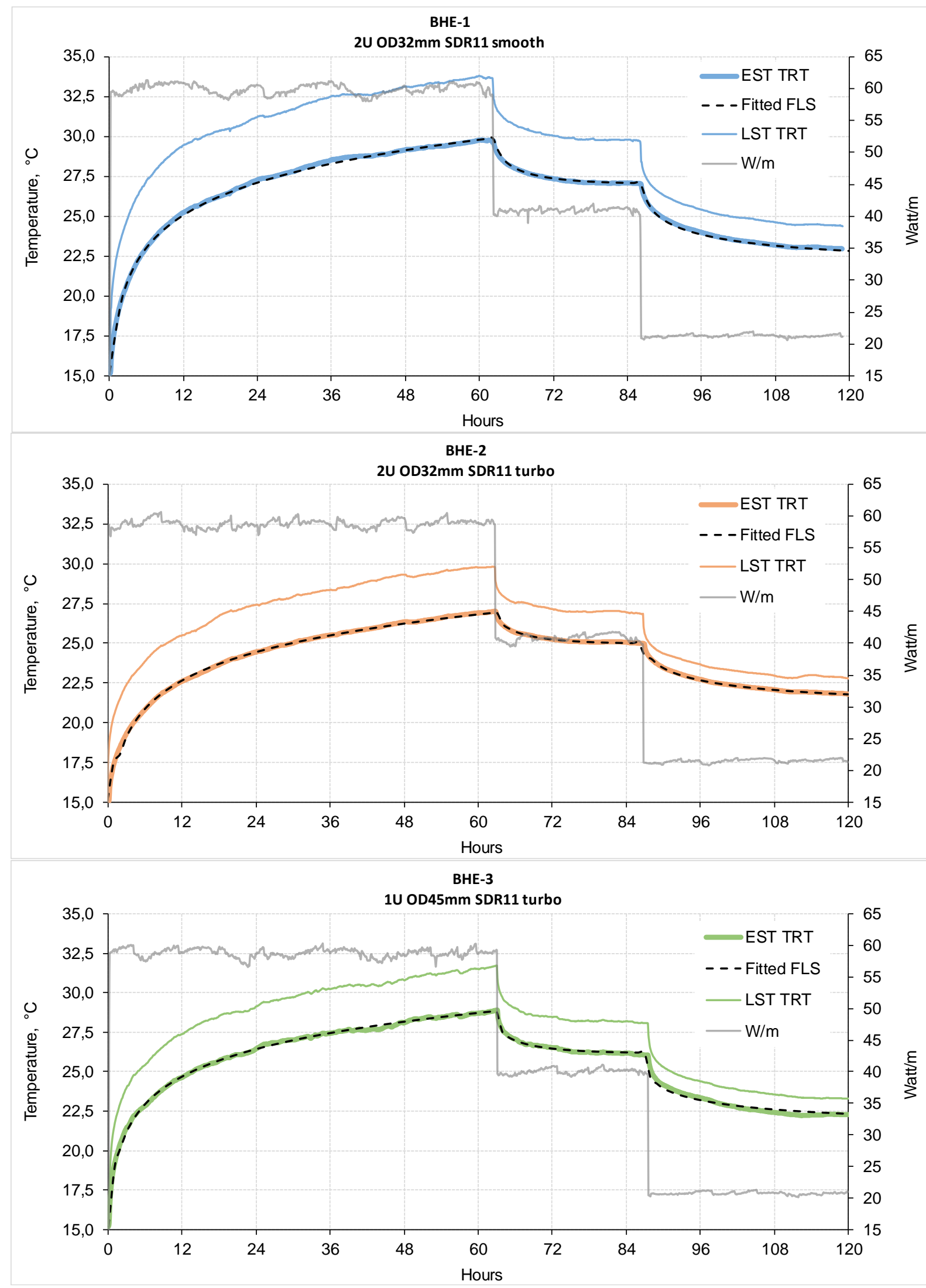

Figure 5. Fitting of measured data with FLS method (use of g-function) for three different pipe type a) 2U-pipe, smooth, D32mm b)2U-pipe, turbo, D32mm c) 1U-pipe, turbo, D45mm. 


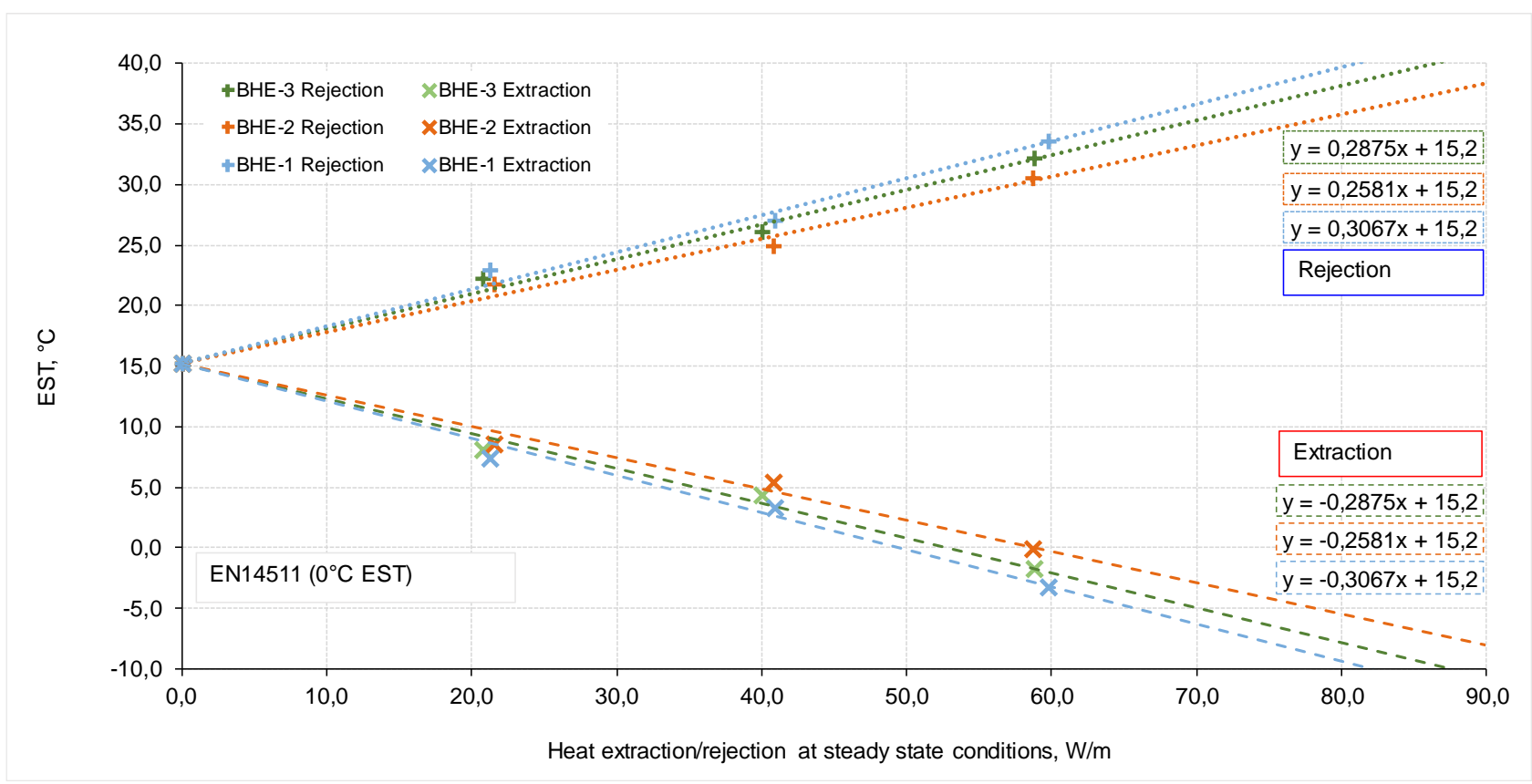

Figure 6. Determining the extraction/rejection heat for three different pipe configurations.

Table 3. Obtained extraction and rejection heat rates from a three BHE and from data presented in Figure 6

\begin{tabular}{lrr}
\hline & $\begin{array}{r}\text { BHE rejection capacity, kW } \\
\text { EST @ 35 } 5^{\circ} \text { C EN14511 }\end{array}$ & $\begin{array}{r}\text { BHE extraction capacity, kW } \\
\text { EST @ 0 }{ }^{\circ} \text { C EN14511 }\end{array}$ \\
\hline BHE-1 2U D32 smooth & $\mathrm{W} / \mathrm{m}$ & $\mathrm{W} / \mathrm{m}$ \\
\hline BHE-2 2U D32 ribbed & 64,7 & 49,6 \\
\hline BHE-3 1U D45 ribbed & 76,7 & 58,9 \\
\hline
\end{tabular}

\section{Conclusion}

Ground thermal conductivity and borehole skin factor, obtained from TRT measurements, are prerequisite for optimized design of the borehole heat exchanger field. Such systems in practice are often unnecessarily oversized as the result of the insecurity factor, or undersized as the result of poor engineering design and nonunderstanding of ground properties. In both cases, this negatively reflects on the economic viability of the geothermal project itself. From this perspective, longer and advanced ground thermal response measurements are cost-effective, as they ensure the longevity of the system and the knowledge of the borehole temperature evolution during entire year. Investigation showed, that in same geological environment, borehole heat exchangers comprised of TurboCollector ${ }^{\mathrm{TM}}$ principle of ribbed inner wall offer higher extraction and rejection rates than the standard and most common system of smooth $2 \mathrm{U}$ pipe exchanger by $6,5 \%$ and $18,7 \%$, respectively (as presented in Table 3.) 


\section{References}

1. Zarrella, A., Emmi, G., Graci, S., De Carli, M., Cultrera, M., Santa, G. D., Galgaro, A., Nertermann, D., Müller, J., Pockelé, L., Mezzasalma, G., Righini, D., Psyk, M., .Bernardi, A., Thermal response testing results of different types of borehole heat exchangers: an analysis and comparison of interpretation methods. Energies 2017; 10(6): 801.

2. Badenes, B., Mateo Pla, M. Á., Lemus-Zúñiga, L. G., Sáiz Mauleón, B., \& Urchueguía, J. F., On the Influence of Operational and Control Parameters in Thermal Response Testing of Borehole Heat Exchangers. Energies 2017; 10(9): 1328.

3. Lamarche, L., Raymond, J., \& Koubikana Pambou, C. H., Evaluation of the internal and borehole resistances during thermal response tests and impact on ground heat exchanger design. Energies 2017; 11(1): 38.

4. Boban, L., Soldo, V., Stošić, J., Filipović, E., Tremac, F., Ground Thermal Response and Recovery after Heat Injection: Experimental Investigation. Transactions of FAMENA 2018; 42(SI-1): 39-50.

5. Kurevija, T., Macenić, M., Strpić, K., Steady-state heat rejection rates for a coaxial borehole heat exchanger during passive and active cooling determined with the novel step thermal response test method. The Mining-Geology-Petroleum Engineering Bulletin 2018; 33(2): 61-71.

6. Kurevija, T., Strpić, K., Koščak-Kolin, S., Applying petroleum the pressure buildup well test procedure on thermal response test-A novel method for analyzing temperature recovery period. Energies 2018; 11(2): 366.

7. Beier, R. A., Mitchell, M. S., Spitler, J. D., Javed, S., Validation of borehole heat exchanger models against multi-flow rate thermal response tests. Geothermics 2018; 71: 55-68.

8. Beier, R. A., Use of temperature derivative to analyze thermal response tests on borehole heat exchangers. Applied Thermal Engineering 2018; 134: 298-309.

9. Urchueguía, J., Lemus-Zúñiga, L. G., Oliver-Villanueva, J. V., Badenes, B., Pla, M., Cuevas, J., How Reliable Are Standard Thermal Response Tests? An Assessment Based on Long-Term Thermal Response Tests Under Different Operational Conditions. Energies 2018; 11(12): 3347.

10. Pasquier P., Interpretation of the first hours of a thermal response test using the time derivative of the temperature. Applied Energy. 2018; 213:56-75.

11. Fossa M, Rolando D, Pasquier P. Pulsated Thermal Response Test experiments and modelling for ground thermal property estimation. IGSHPA Research Track; 2018 Sep 18 - 20; Stockholm, Sweden.

12. Fourier J., Theorie analytique de la chaleur, par M. Fourier. Chez Firmin Didot, père et fils. 1822.

13. Ingersoll L. R., Zobel O. J., An introduction to the mathematical theory of heat conduction. Boston, USA: Ginn and Company; 1913.

14. Chiasson, A. D. Geothermal heat pump and heat engine systems: Theory and practice. Hoboken, USA: John Wiley \& Sons Ltd; 2016.

15. Carslaw, H. S., Jaeger, J. C., Conduction of heat in solids. Oxford: Clarendon Press; 1959.

16. Eskilson P., Thermal Analysis of Heat Extraction Boreholes [dissertation]. Lund, Sweden, University of Lund; 1987.

17. Matthews, C.S., Russell D.G, Pressure Buildup and Flow Tests in Wells. Dallas, USA: Society of petroleum engineers of AIME; 1967.

18. Lee, J., Well Testing. Richardson, Texas; Society of Petroleum Engineers of AIME, SPE: 1982

19. Gehlin, S., Thermal Response test: method development and evaluation [dissertation]. Lulea, Sweden, Lulea University of Technology; 2002.

20. Claesson, J., Eskilson, P., Conductive heat extraction by a deep borehole. Analytical studies. Dep. of Mathematical Physics, University of Lund: 1987.

21. Al-Khoury, F. Computational Modeling of Shallow Geothermal System. London, UK: CRC Press; 2012.

22. Šikić, K., Basch, O., Šimunić, A., Basic geological map of SFRJ. Zagreb, Croatia: Croatian Geological Survey:1978.

23. Acuña, J., Improvements of U-pipe borehole heat exchangers [licenciate thesis]. Stockholm, Sweden, KTH School of Industrial Engineering and Management; 2010

24. Patent: Ojala J. et al, Pipe collector for heat pump systems US9546802 (B2) — 2017-01-17 


\section{Nomenclature}

c specific heat, $\mathrm{J} /\left(\mathrm{kg}{ }^{\circ} \mathrm{C}\right)$

Ei exponential integral

g dimensionless g-function, -

$\mathrm{H}$ depth, $\mathrm{m}$

$\dot{m}$ mass flow rate, $\mathrm{kg} / \mathrm{s}$

$\mathrm{r}$ radius, $\mathrm{m}$

$\mathrm{rb}$ borehole radius, $\mathrm{m}$

$\mathrm{R}$ thermal resistance, ${ }^{\circ} \mathrm{C} \mathrm{m} / \mathrm{W}$

$R_{\mathrm{ff}} \quad$ theral resistance between inlet and outlet concentric pipe, ${ }^{\circ} \mathrm{C} \mathrm{m} / \mathrm{W}$

$R_{\text {fig }}$ thermal resistance between inlet pipe fluid and grout, ${ }^{\circ} \mathrm{C} \mathrm{m} / \mathrm{W}$

$R_{\text {fog }}$ thermal resistance between outlet pipe fluid and grout, ${ }^{\circ} \mathrm{C} \mathrm{m} / \mathrm{W}$

$\mathrm{R}_{g g}$ thermal resistance due to inter-grout exchange, ${ }^{\circ} \mathrm{C} \mathrm{m} / \mathrm{W}$

$\mathrm{Rgs}_{\mathrm{gs}}$ thermal resistance due to grout-soil exchange, ${ }^{\circ} \mathrm{C} \mathrm{m} / \mathrm{W}$

$\mathrm{t}$ time, $\mathrm{h}$

$t_{s}$ time at which steady state heat transfer is achieved, $\mathrm{h}$

$\mathrm{T}$ temperature, ${ }^{\circ} \mathrm{C}$

$\mathrm{T}(\mathrm{r}, \mathrm{t}) \quad$ temperature in function of radius and time, ${ }^{\circ} \mathrm{C}$

$\mathrm{T}_{0}$ undisturbed ground temperature $\left({ }^{\circ} \mathrm{C}\right)$

$\mathrm{T}_{\mathrm{f}}$ borehole fluid mean temperature $\left({ }^{\circ} \mathrm{C}\right)$

$\mathrm{Tb}$ borehole wall temperature $\left({ }^{\circ} \mathrm{C}\right)$

$q^{\prime}$ heat power per meter of a borehole, $\mathrm{W} / \mathrm{m}$

$\mathrm{u}$ integral parameter

\section{Greek symbols}

$\alpha$ soil thermal diffusivity, $\mathrm{m}^{2} / \mathrm{h}$

$\lambda$ thermal conductivity, $\mathrm{W} /\left(\mathrm{m}{ }^{\circ} \mathrm{C}\right)$

$\gamma$ Euler's constant $(0,5772)$

\section{Subscripts and superscripts}

b borehole

g grout

$\mathrm{f}$ fluid

\section{Abbreviations}

EST Entering source temperature

LST Leaving source temperature

SPF Seasonal performance factor

TRST Steady-state thermal response step test

TRT Thermal response test

BHEBorehole heat exchanger 